\title{
A LOW-COST ADSORBENT COCONUT WASTE ASH ACTIVATED NaCI FOR METHYLENE BLUE REMOVAL
}

\author{
Pujiana, N. ${ }^{1}$, Yulianti, E. ${ }^{1 *}$, Rahmatullah, A. ${ }^{2}$, Khalifah, S.N. ${ }^{1}$, Istighfarini, V.N. ${ }^{1}$ \\ ${ }^{1}$ Department of Chemistry, Universitas Islam Negeri Maulana Malik Ibrahim Malang \\ Jl. Gajayana No. 50 Malang 65144 \\ ${ }^{2}$ Chemical Engineering, Politeknik Negeri Malang
}

Received: $13^{\text {th }}$ December 2019; Revised: 30 $0^{\text {th }}$ January 2020; Accepted: $7^{\text {th }}$ April 2020

\begin{abstract}
Removal methylene blue from water using coconut waste ash activated by $\mathrm{NaCl}$ is studied in this paper. The characteristic of morphology and pore structure of coconut waste ash is analyzed using SEM, show that pores were formed after activation. XRF analysis revealed that the coconut waste ash before activation contains $20,19 \%$ of $\mathrm{Si}$. The effect of $\mathrm{NaCl}$ concentration on the adsorption behavior is investigated. The results show that the optimum concentration of $\mathrm{NaCl}$ to activating the coconut waste ash is $300 \mathrm{ppm}$. The adsorption capacity of coconut waste ash without activation, NaCl-activated coconut waste ash on $200 \mathrm{ppm}, 300 \mathrm{ppm}$, and $400 \mathrm{ppm}$ is $1.103 \mathrm{mg} / \mathrm{g}, 1.152 \mathrm{mg} / \mathrm{g}, 1.2102 \mathrm{mg} / \mathrm{g}$, and $1.1109 \mathrm{mg} / \mathrm{g}$ respectively.
\end{abstract}

Keywords: Adsorbent; Coconut Waste Ash; Methylene Blue; $\mathrm{NaCl}$

\section{Introduction}

Today, water pollution is a serious problem in the world. Eliminating the dye from effluents of chemical industries such as paper, textile, leather, plastic, and rubber has persisted an issue of the rising burden to the environmentalists. ${ }^{1,2}$ Therefore dye elimination has been a very critical but defying area of wastewater treatment. Some dye removal process of wastewater has been carried out, such as coagulation, membrane separation, biological treatment, and adsorption techniques. $^{2}$

The adsorption of dyes from wastewater is the most powerful for the decolorization of various classes of dyes from wastewater. ${ }^{3,4}$ There is a crucial need for a choice adsorption method with harmless, cheap, and narrowly accessible for the prosperous application of wastewater treatment. ${ }^{1}$ Recently, some adsorbents are developed from coconut-based. Activated carbon from coconut shell for RB19, ${ }^{4}$ methylene blue ${ }^{2}$ and lead (II) ${ }^{5}$ removal, waste from coconut coir to desulfurization, ${ }^{6}$ coconut coir pith for nickel adsorption, ${ }^{7}$ coconut coir powder to remove copper, nickel, and cadmium, ${ }^{8}$ coconut husk for removal $\mathrm{Pb}, \mathrm{Cu}, \mathrm{Ni}$ and $\mathrm{Zn},{ }^{9}$ coconut husk for removal methylene blue and congo red, ${ }^{10}$ and charcoal from coconut coir to adsorb levofloxacin. ${ }^{11}$

Sodium chloride is a strong dehydrating agent that can increase the formation of pore structure. ${ }^{12} \mathrm{NaCl}$ as activator agents can increase the effectiveness of adsorbent in removing $\mathrm{Cr}(\mathrm{VI}) .{ }^{13}$ Methylene blue is one of a cationic dye generally used in coloring techniques and has been periodically investigated since its strong adsorption on solids, which function as a model compound for adsorption studies of organic impurities in aqueous solutions. ${ }^{14}$

This research aims to inspect the utilization of cheaper and environmentally friendly $\mathrm{NaCl}$ activated-coconut waste ash as bio-sorbents to confirm their efficiency in removing methylene blue from the water underneath distinctive optimized conditions in the laboratory.

\footnotetext{
*Corresponding author:

E-Mail: enyyulianti@uin-malang.ac.id
} 


\section{Methods}

\section{Materials}

The adsorbent, coconut waste ash, was obtained from the tofu industry, Malang Indonesia. Coconut waste is waste from coconut coir and coconut shell. About $200 \mathrm{~g}$ of ash used to be washed with distilled water twice, followed by drying in an oven at 110 ${ }^{\circ} \mathrm{C}$ for $24 \mathrm{~h}$, sieved to obtain particle sizes 120 mesh and subsequently saved in vacuum desiccators. Other reagents include $\mathrm{HCl}$ (pa), $\mathrm{NaCl}$ (technical), $\mathrm{AgNO}_{3}$ (pa), methylene blue (pa) and distilled water. Instruments employed for the work include UV-visible spectrophotometer (Varian carry), SEMEDX (FEI inspect-S50), and pH meter.

\section{Adsorbent Preparation}

About $200 \mathrm{~g}$ of ash was sieved to obtain particle sizes 120 mesh. It was soaked in $\mathrm{NaCl}$ solution $(200,300$, and $400 \mathrm{ppm})$ in the ratio $1: 4 \mathrm{w} / \mathrm{v}$ and shake at $45^{\circ} \mathrm{C}(300 \mathrm{rpm})$ for five $h$. The samples were heated in a furnace at $450{ }^{\circ} \mathrm{C}$ for 45 minutes, followed by washing with $0.1 \mathrm{M} \mathrm{HCl}$ and shake for one $\mathrm{h}$ and allowed to stand $12 \mathrm{~h}$. The samples were washed with hot water until free $\mathrm{Cl}^{-}$ (checked with $\mathrm{AgNO}_{3} 0.1 \mathrm{~N}$ ), and the filtrate was neutral. The sample then dried at $105{ }^{\circ} \mathrm{C}$ for $24 \mathrm{~h}$.

\section{Determination of surface area}

Methylene blue solution was used for the determination of the surface area of coconut waste ash. It was started from finding the maximum wavelength of absorption $\left(\lambda_{\max }\right)$ of methylene blue in the range of $\mathrm{pH} 3-12,5$, determination of stability time of methylene blue, preparation of calibration curve, and the determination of the coconut waste ash's surface area. Methylene blue solutions contacted with adsorbent were kept at $\mathrm{pH} 3$.

\section{Adsorption of methylene blue}

About $50 \mathrm{~mL}$ of methylene blue (16 ppm) was added into $0.5 \mathrm{~g}$ of non-activated ash followed by covering the erlenmeyer with aluminum foil. The samples were shaken at $100 \mathrm{rpm}$ for 15 minutes and allowed to stand for 30 minutes. Then the filtering and the remaining methylene blue were measured. The concentration was analyzed using UVVis spectroscopy at the maximum wavelength, optimum $\mathrm{pH}$, and in the range of stability time of methylene blue. The treatment was repeated with the same procedure for $\mathrm{NaCl}$-activated ash of 200 ppm, 300 ppm, and 400 ppm.

\section{Result and Discussion}

\section{Analysis using SEM-EDX}

The element composition of coconut waste ash is shown from EDX analysis in Fig. 1 and summarized in Table 1. Table 1 shows that silica is the most content. Other elements such as $\mathrm{K}, \mathrm{O}, \mathrm{Ca}, \mathrm{P}, \mathrm{Mg}, \mathrm{Na}, \mathrm{Cl}, \mathrm{S}$, and $\mathrm{Al}$ in the following value. Fig.2a and $2 \mathrm{~b}$ show the profiles of coconut waste ash before and after activation, respectively.

Table 1. The elemental composition of coconut waste ash from EDX analysis

\begin{tabular}{cc}
\hline Elements & $\begin{array}{c}\text { Wt (\%) Before } \\
\text { activation }\end{array}$ \\
\hline $\mathbf{O}$ & 16.95 \\
$\mathbf{N a}$ & 2.67 \\
$\mathbf{M g}$ & 3.15 \\
$\mathbf{A l}$ & 0.65 \\
$\mathbf{S i}$ & 20.19 \\
$\mathbf{P}$ & 3.31 \\
$\mathbf{K}$ & 18.36 \\
$\mathbf{C l}$ & 1.77 \\
$\mathbf{S}$ & 1.43 \\
$\mathbf{C a}$ & 9.51 \\
\hline
\end{tabular}

Figure 2a shows the outer surface structure of coconut waste ash was variant in nature with major porosity, along with a sequence of irregular shape cavities and pores. Fig. $2 b$ shows that pores were formed after activation, which shows $\mathrm{NaCl}$ is the potential in producing pores in coconut waste ash. The pore formation can be caused by the activator evaporation from the coconut waste ash surface throughout the process of physical-activation. These pores had been formed due to the evaporation of impregnated $\mathrm{NaCl}$. The addition of $\mathrm{HCl}$ leads to a reduced content of metals oxides. So the 
resulting solids are porous and have a larger surface area. The presence of defined pore shape is prominently essential as it influences the adsorption rate of methylene blue.

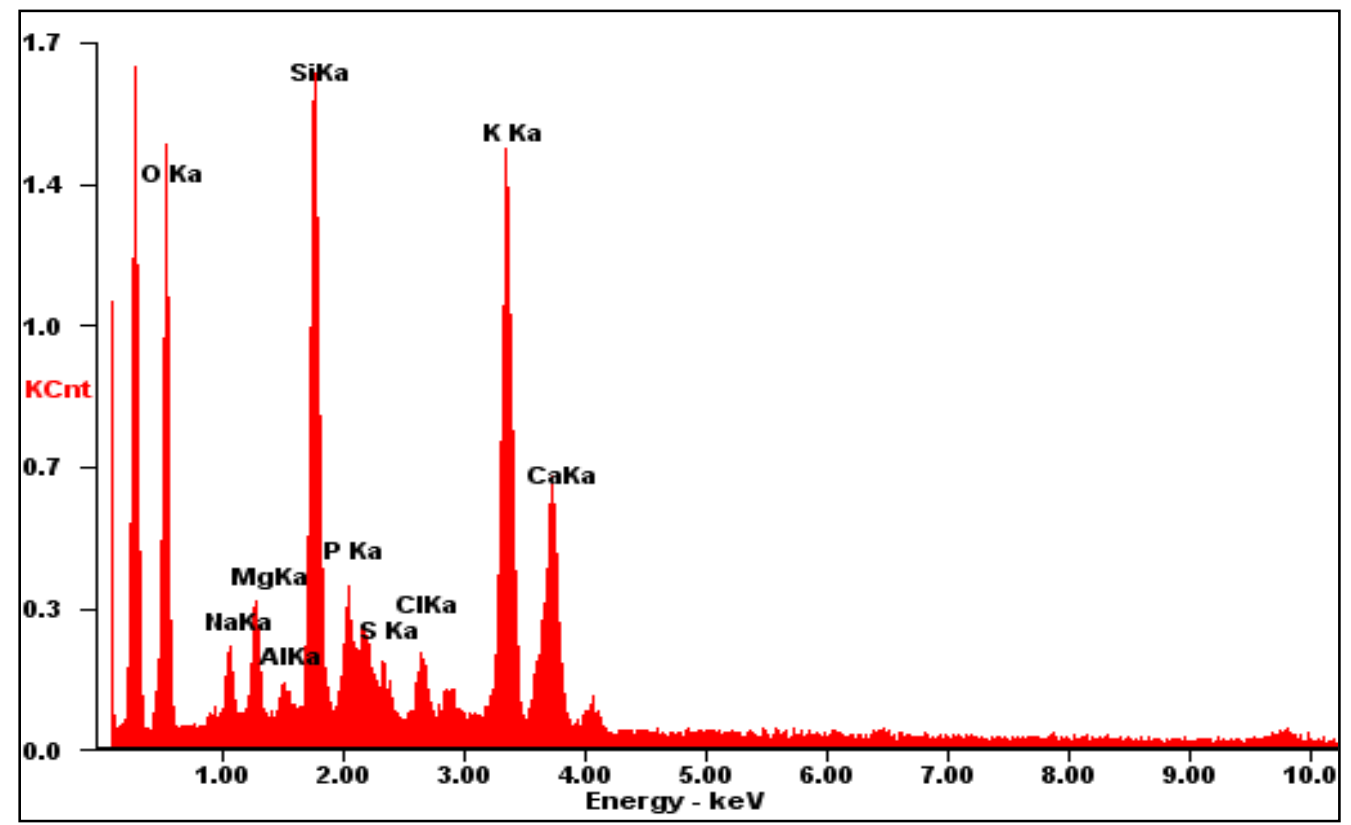

Figure 1. EDX spectra of coconut waste ash before activation
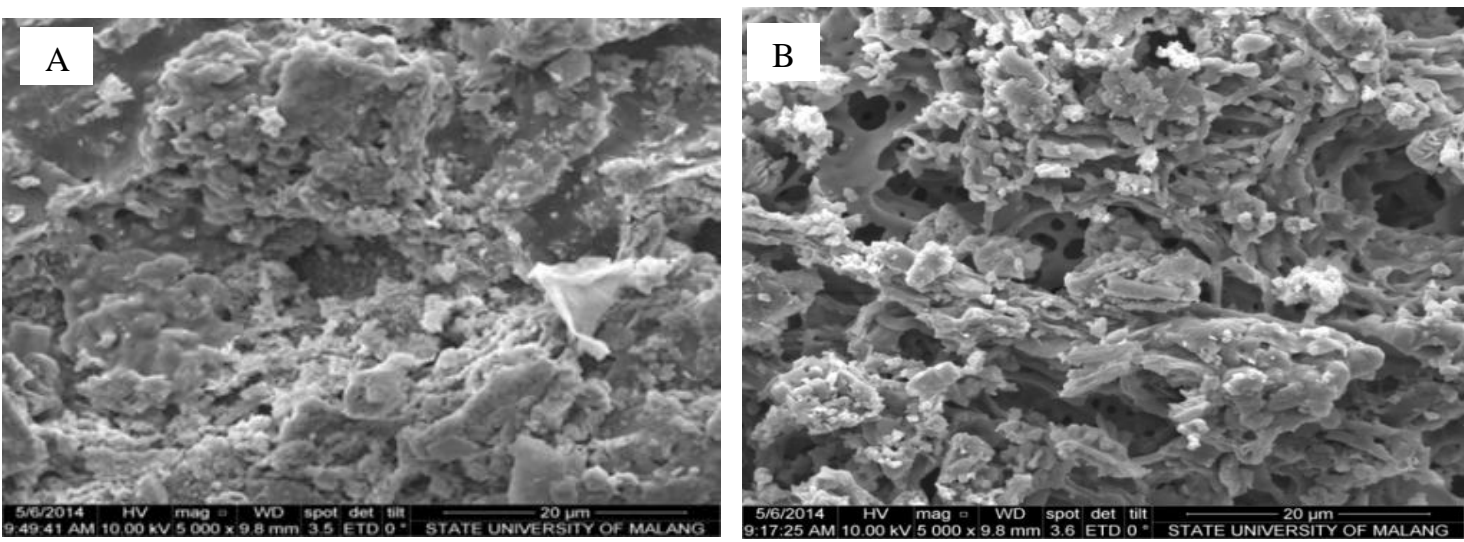

Figure 2. SEM images of coconut waste ash: (a) before activation; (b) after activation using $\mathrm{NaCl} 300$ ppm

\section{Determination of surface area}

Methylene blue solution was used to determination of the surface area of coconut waste ash by three steps. The determination of $\lambda_{\max }$ of absorption was once the preliminary step. This step was once completed by measurement of absorbances of the methylene blue solution $16 \mathrm{ppm}$ with ranges of wavelength from $600-700 \mathrm{~nm}$ in the variation of $\mathrm{pH}$. The result is shown in Table 2.

Determination of the stability of methylene blue aims to determine the stable measurement time on methylene blue by measuring the results of the reaction or the formation of color. Determination of the stability time is measured in minutes 0,10 , $20,30,40,50,60,70,80$, and 90 with a UVVis spectrophotometer at the optimum wavelength. Figure 3 shows that the stability of methylene blue in the range of 30-50 minutes. After 50 minutes, the absorbance of methylene blue decreases to the 90th minute.

Measure the absorbance of methylene blue in the variation of concentration (1.0; $2.0 ; 3.0 ; 4.0$ and $5.0 \mathrm{mg} / \mathrm{L}$ ) at the $\lambda_{\max }$ used to 
be finished to make the calibration curve. The data obtained was used to make the calibration curve. It is shown in Figure 4. The linear regression equation is $\mathrm{y}=0.2796 \mathrm{x}$ $-0.006\left(\mathrm{R}^{2}=0.9997\right)$. The remaining concentration of the methylene blue that was unably adsorbed by the coconut waste ash is measure by this equation.

The methylene blue adsorbed by coconut waste ash was used to interpret the surface area of the coconut waste ash. Hence, the amounts of methylene blue were contacted with the coconut waste ash. Absorbances of the methylene blue remained in each $\mathrm{NaCl}$ concentration are used to substitute the $\mathrm{y}$ value of the regression equation, and consequently, the $x$-values of the equation could be calculated. The amount of methylene blue adsorbed is the difference between the initial concentration $(16 \mathrm{mg} / \mathrm{L})$ and the remaining amount.

Table 2. The effect of $\mathrm{pH}$ on determining $\lambda_{\max }$

\begin{tabular}{ccc}
\hline $\mathbf{p H}$ & Wavelength $(\mathbf{n m})$ & Absorbance \\
\hline $\mathbf{3}$ & $\mathbf{6 6 5 . 1}$ & $\mathbf{1 . 1 2 5}$ \\
$\mathbf{5}$ & 665.1 & 0.996 \\
$\mathbf{7}$ & 664.0 & 0.905 \\
$\mathbf{9}$ & 665.1 & 0.915 \\
$\mathbf{1 1}$ & 663.0 & 0.872 \\
$\mathbf{1 2 . 5}$ & 665.1 & 0.633 \\
\hline
\end{tabular}

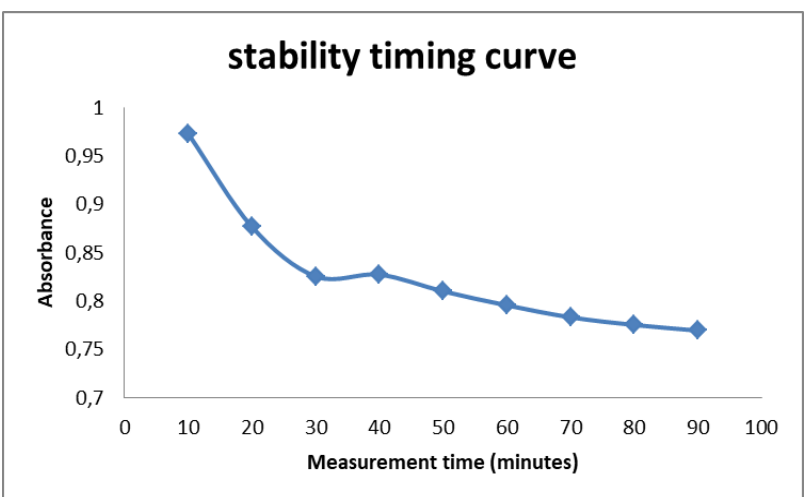

Figure 3. The stability timing curve of methylene blue

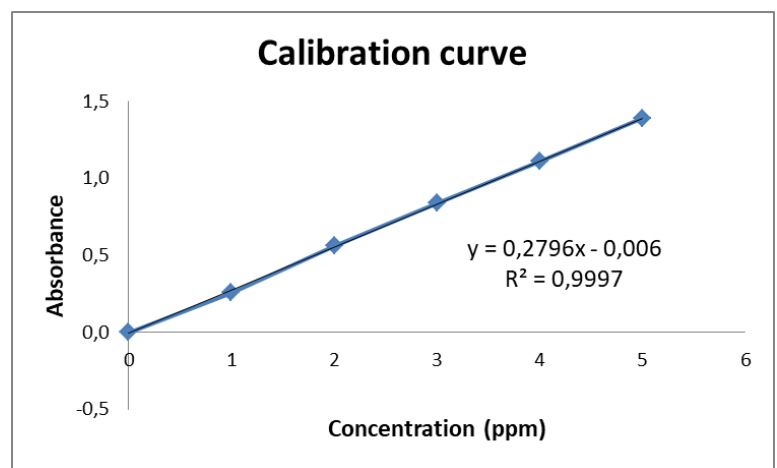

Figure 4. The calibration curve of methylene blue

The output of the calculation was used to make a curve: the number of adsorbed methylene blue (x) per gram of adsorbent $(\mathrm{m})$ versus time of contact. Those curves are shown in Figure 5.

Effect of activator concentration on methylene blue removal

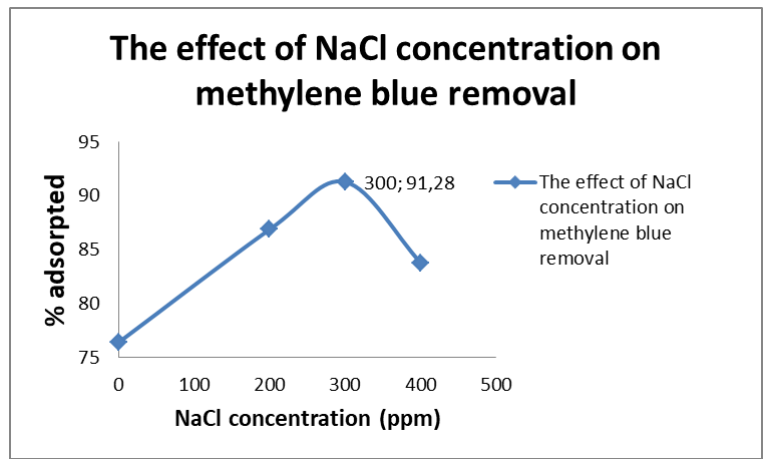

Figure 5. The effect of $\mathrm{NaCl}$ concentration on methylene blue removal

The absorbance measurement of methylene blue after adsorption is performed at optimum condition, and it is at wavelength $665.1 \mathrm{~nm}, \mathrm{pH} \mathrm{3}$, and at the range time stability of methylene blue ( 30 - 50 minutes). Figure 5 shows that the adsorption ability of the coconut waste ash after $\mathrm{NaCl}$-activation is increase. The optimum concentration of $\mathrm{NaCl}$ is $300 \mathrm{ppm}$, and methylene blue was adsorbed until $91.28 \%$.

The foremost quantity of methylene blue adsorbed should be used to calculate the surface area of adsorbent by the usage of equation ${ }^{15}$ : 
SA is the surface area of adsorbent $\left(\mathrm{m}^{2} / \mathrm{g}\right)$, $\mathrm{Wm}$ is the number of methylene blue adsorbed, $\mathrm{N}$ is the Avogadro's number $\left(6.022 \times 10^{23} \mathrm{~mol}^{-1}\right), \mathrm{A}$ is the surface area of $1 \mathrm{~mol}$ methylene blue $\left(197.10^{-20} \mathrm{~m}^{2} / \mathrm{g}\right)$, and $\mathrm{M}$ is the mass of $1 \mathrm{~mol}$ methylene blue $(320.5 \mathrm{~g} / \mathrm{mol})$.

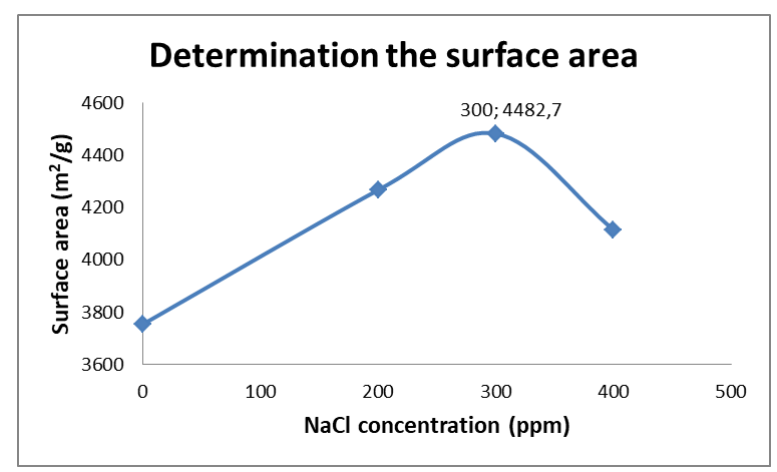

Figure 6. The methylene blue adsorbed by the $\mathrm{NaCl}$-activated coconut waste ash at various concentrations.

Figure 5 shows that the optimum surface area of natural zeolite was obtained when it was activated with $300 \mathrm{ppm}$ of $\mathrm{NaCl}$. The activation using $\mathrm{NaCl}$ solution produces the higher surface area of the adsorbent. The result might be due to the ability of $\mathrm{NaCl}$ to exchange the cation.

The higher the surface area of the ash, the greater the adsorption capacity, so that the \% adsorbed is greater. But, the higher the absorbance, the lower the adsorption capacity, because the adsorption capacity is determined by decreasing the absorbance of methylene blue.

Adsorption of methylene blue by the active site $\left(\mathrm{SiO}_{2}\right)$ occurs if there is a tug between the active site and methylene blue. The more active sites found in the pores and surface of the ash then the methylene blue that is adsorbed is also getting bigger, supported by the greater pores of the ash so that more methylene blue can be absorbed.

Coconut waste ash contains silicon dioxide, which will react with $\mathrm{OH}^{-}$to form $\mathrm{SiO}^{-}$. So that, when adsorbing methylene blue, there will be a reaction between oxygen (negatively charged) bonded to silicon dioxide with nitrogen (positively charged) bonded to the methylene blue. ${ }^{16}$

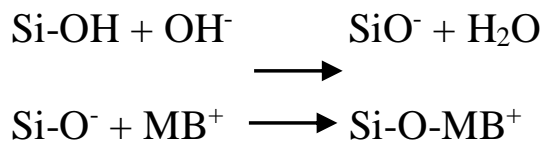

\section{Conclusion}

The results of the experiment show that activation using $\mathrm{NaCl}$ creating the pore in the surface of coconut waste ash and increasing the adsorption capacity. The adsorption capacity of $\mathrm{NaCl}$-activated coconut waste ash on 200 ppm, 300 ppm, 400 ppm, and without activation is $1.152 \mathrm{mg} / \mathrm{g}, 1.2102 \mathrm{mg} / \mathrm{g}, 1.1109$ $\mathrm{mg} / \mathrm{g}$ and $1.103 \mathrm{mg} / \mathrm{g}$ respectively. Activated ash using $\mathrm{NaCl} 300 \mathrm{ppm}$ can remove the methylene blue up to $91.28 \%$.

\section{References}

1. Karthik R, Muthezhilan R, Jaffar Hussain A, Ramalingam K, Rekha V. Effective Removal of Methylene Blue Dye from Water using Three Different Low-cost Adsorbents. Desalination Water Treat. 2016;57(23):10626-10631. doi:10.1080/19443994.2015.1039598

2. Khuluk RH, Rahmat A. Removal of Methylene Blue by Adsorption onto Activated Carbon from Coconut Shell (Cocous nucifera L.). :12.

3. Mouni L, Belkhiri L, Bollinger J-C, et al. Removal of Methylene Blue from Aqueous Solutions by Adsorption on Kaolin: Kinetic and Equilibrium Studies. Appl Clay Sci. 2018;153:38-45. doi:10.1016/j.clay.2017.11.034

4. Isah A. U, Abdulraheem G, Bala S, Muhammad S, Abdullahi M. Kinetics, Equilibrium and Thermodynamics Studies of C.I. Reactive Blue 19 Dye Adsorption on Coconut Shell based Activated Carbon. Int Biodeterior Biodegrad. 2015;102:265273. doi:10.1016/j.ibiod.2015.04.006

5. Song C, Wu S, Cheng M, Tao P, Shao M, Gao G. Adsorption Studies of Coconut Shell Carbons Prepared by $\mathrm{KOH}$ Activation for Removal of Lead(II) from Aqueous Solutions. Sustainability. 2013;6(1):86-98. doi:10.3390/su6010086

6. Ahmed MdJK, Ahmaruzzaman M. Adsorptive Desulfurization of Feed Diesel 
using Chemically Impregnated Coconut Coir Waste. Int J Environ Sci Technol. 2015;12(9):2847-2856. doi:10.1007/s13762-014-0654-4

7. Ratan S, Singh I, Sarkar J, RM N. The Removal of Nickel from Waste Water by Modified Coconut Coir Pith. Chem Sci J. 2016;7(3). doi:10.4172/21503494.1000136

8. Aravind C, Chanakya K, Mahindra K. Removal of Heavy Metals from Industrial Waste Water using Coconut Coir. :3.

9. Malik R, Dahiya S, lata S. An Experimental and Quantum Chemical Study of Removal of Utmostly Quantified Heavy Metals in Wastewater using Coconut Husk: A Novel Approach to Mechanism. Int J Biol Macromol. 2017;98:139-149. doi:10.1016/j.ijbiomac.2017.01.100

10. Aung HM, Htun YY. Study on Colour Removal of Organic Dyes (Methylene Blue and Congo Red ) by using Coconut Husk. 2018:8.

11. Limbikai SS, Deshpande NA, Kulkarni RM, Khan AAP, Khan A. Kinetics and Adsorption Studies on the Removal of Levofloxacin using Coconut Coir Charcoal Impregnated with $\mathrm{Al}_{2} \mathrm{O}_{3}$ Nanoparticles. Desalination Water Treat. 2016;57(50):23918-23926. doi:10.1080/19443994.2016.1138330

12. Rashidi NA, Yusup S. A Review on Recent Technological Advancement in the Activated Carbon Production from Oil Palm Wastes. Chem Eng J. 2017;314:277-290. doi:10.1016/j.cej.2016.11.059

13. Mise S, Patil TN. Adsorption Studies of Chromium(VI) on Activated Carbon Derived from Mangifera indica (Mango) Seed Shell. J Inst Eng India Ser A. 2015;96(3):237-247. doi:10.1007/s40030-015-0124-0

14. Bedin KC, Martins AC, Cazetta AL, Pezoti O, Almeida VC. KOH-activated Carbon Prepared from Sucrose Spherical Carbon: Adsorption Equilibrium, Kinetic and Thermodynamic Studies for Methylene Blue removal. Chem Eng J.
2016;286:476-484.

doi:10.1016/j.cej.2015.10.099

15. Yukselen Y, Kaya A. Suitability of the Methylene Blue Test for Surface Area, Cation Exchange Capacity and Swell Potential Determination of Clayey Soils. Eng Geol. 2008;102(1-2):38-45. doi:10.1016/j.enggeo.2008.07.002

16. Alzaydien AS. Adsorption of Methylene Blue from Aqueous Solution onto a Low-Cost Natural Jordanian Tripoli. Am J Environ Sci. 2009;5(3):197-208. doi:10.3844/ajessp.2009.197.208 